Australian

National

University

Crawford School of Public Policy

\title{
CAMA
}

Centre for Applied Macroeconomic Analysis

\section{Financial Uncertainty and Real Activity: The Good, the Bad, and the Ugly}

\section{CAMA Working Paper 67/2020 July 2020}

Giovanni Caggiano

Monash University

University of Padova

Centre for Applied Macroeconomic Analysis, ANU

Efrem Castelnuovo

University of Melbourne

University of Padova

Centre for Applied Macroeconomic Analysis, ANU

Richard Kima

Monash University

Silvia Delrio

Bank of Italy 


\section{Abstract}

This paper quantifies the finance uncertainty multiplier (i.e., the magnifying effect of the real impact of uncertainty shocks due to financial frictions) by relying on two historical events related to the US economy, i.e., the large jump in financial uncertainty occurred in October 1987 (which was not accompanied by a deterioration of the credit supply conditions), and the comparable jump in financial uncertainty in September 2008 (which went hand-in-hand with an increase in financial stress). Working with a VAR framework and a set-identification strategy which focuses on - but it is not limited to - restrictions related to these two dates, we estimate the finance uncertainty multiplier to be equal to 2 , i.e., credit supply disruptions are found to double the negative output response to an uncertainty shock. We then employ our model to estimate the overall economic cost of the COVID-19-induced uncertainty shock under different scenarios. Our results point to the possibility of a cumulative yearly loss of industrial production as large as $31 \%$ if credit supply gets disrupted. Liquidity interventions that keep credit conditions as healthy as they were before the COVID-19 uncertainty shock are found to substantially reduce such loss.

\section{Keywords}

Uncertainty shocks, finance-uncertainty multiplier, set-identification, VAR, financial frictions, COVID-19

\section{JEL Classification}

C32, E32

\section{Address for correspondence:}

(E) cama.admin@anu.edu.au

\section{ISSN 2206-0332}

The Centre for Applied Macroeconomic Analysis in the Crawford School of Public Policy has been established to build strong links between professional macroeconomists. It provides a forum for quality macroeconomic research and discussion of policy issues between academia, government and the private sector.

The Crawford School of Public Policy is the Australian National University's public policy school, serving and influencing Australia, Asia and the Pacific through advanced policy research, graduate and executive education, and policy impact. 


\title{
Financial Uncertainty and Real Activity: The Good, the Bad, and the Ugly *
}

\author{
Giovanni Caggiano \\ Monash University \\ University of Padova \\ Centre for Applied Macreoconomic Analysis \\ Efrem Castelnuovo \\ University of Melbourne \\ University of Padova \\ Centre for Applied Macreoconomic Analysis \\ Richard Kima \\ Monash University \\ Silvia Delrio \\ Bank of Italy
}

June 2020

\begin{abstract}
This paper quantifies the finance uncertainty multiplier (i.e., the magnifying effect of the real impact of uncertainty shocks due to financial frictions) by relying on two historical events related to the US economy, i.e., the large jump in financial uncertainty occurred in October 1987 (which was not accompanied by a deterioration of the credit supply conditions), and the comparable jump in financial uncertainty in September 2008 (which went hand-in-hand with an increase in
\end{abstract}

\footnotetext{
${ }^{*}$ We would like to thank Renée Fry-McKibbin, Martin Fukac, Laurent Ferrara, Benoit Mojon, James Morley, Giovanni Pellegrino, Tim Robinson, Rodney Strachan, Kerem Tuzcuoglu, and participants to various conferences, workshops, seminars, and webinars for valuable suggestions. Financial support by the Australian Research Council via the DP160102281 and DP160102654 is gratefully acknowledged. The views expressed in this paper are those of the authors and do not involve the responsibility of the Bank of Italy. Corresponding author: Efrem Castelnuovo - efrem.castelnuovo@gmail.com .
} 
financial stress). Working with a VAR framework and a set-identification strategy which focuses on - but it is not limited to - restrictions related to these two dates, we estimate the finance uncertainty multiplier to be equal to 2, i.e., credit supply disruptions are found to double the negative output response to an uncertainty shock. We then employ our model to estimate the overall economic cost of the COVID-19-induced uncertainty shock under different scenarios. Our results point to the possibility of a cumulative yearly loss of industrial production as large as $31 \%$ if credit supply gets disrupted. Liquidity interventions that keep credit conditions as healthy as they were before the COVID-19 uncertainty shock are found to substantially reduce such loss.

Keywords: Uncertainty shocks, finance-uncertainty multiplier, set-identification, VAR, financial frictions, COVID-19.

JEL codes: C32, E32. 


\section{Introduction}

The COVID-19 shock that forcefully hit the US economy in March 2020 injected a level of uncertainty in financial markets comparable to, if not higher than, the one associated to the 2007-09 Great Recession and, before that, to the Black Monday (Baker, Bloom, Davis, Kost, Sammon, and Viratyosin (2020)). This is bad news. A large increase in financial uncertainty was most likely one of the relevant drivers of the US Great Recession (Bloom (2014), Basu and Bundick (2017), Pellegrino, Caggiano, and Castelnuovo (2019), Benati (2019)). A connected strand of the literature stresses the role played by the toxic "high uncertainty-high financial stress" tandem. ${ }^{1}$ Had financial markets functioned in a business-as-usual fashion in 2007-09, the output loss experienced by the US economy because of the increase in uncertainty would have likely been substantially lower. Alfaro, Bloom, and Lin (2019) coin the term "finance-uncertainty multiplier" (FUM) to indicate the role played by financial frictions in magnifying the real effects of uncertainty shocks.

How large is the FUM? Addressing this question is crucial for policymakers. If the FUM is large, liquidity injections following shocks associated to spikes in uncertainty are the most obvious policy move to avoid repeating another Great Recession. Differently, if the financial multiplier is small, rapid interventions to kill uncertainty (via clear and credible communication of future policy moves, e.g., forward guidance policies, or the quick development of a testing, tracing, and treating plan for pandemics like COVID19) should come first in policymakers' agendas. ${ }^{2}$ Unfortunately, separately identifying the impact of spikes in uncertainty and the role of financial frictions in the data is a formidable challenge in applied work (Stock and Watson (2012)). Figure 1 explains why. The Figure shows the evolution of the VXO, a proxy of financial uncertainty, and that of the excess bond premium (a proxy for credit supply disruptions proposed by Gilchrist and Zakrajšek (2012), EBP hereafter) over the last five decades. ${ }^{3}$ Financial volatility displays three distinct peaks, i.e., the Black Monday one, the one occurred during the Great Recession, and the recent COVID-19 one. The toxic uncertainty-financial stress

\footnotetext{
${ }^{1}$ See Gertler and Gilchrist (2017) for an analysis of financial market disruptions in the US during the Great Recession, and Bloom (2014) and Castelnuovo (2019) for contributions on the business cycle effects of uncertainty shocks.

${ }^{2}$ For evidence in favor of the correlation between the VIX and the growth rate of new COVID-19 cases, see https://www.sifma.org/resources/news/podcast-vix-and-the-virus/ .

${ }^{3}$ The excess bond premium, estimated by Gilchrist and Zakrajšek (2012), is the component of corporate bond credit spreads that is not directly attributable to expected default risk.
} 
tandem occurred during the Great Recession is evident in the data. This correlation is the reason why separating first and second-moment financial shocks is complicated. A qualitatively similar pattern, due to the COVID-19 shock, was starting to take place in March 2020, but prompt and massive fiscal and monetary policy interventions successfully contained credit supply disruptions, whose materialization would have probably led to an even uglier economic outcome. ${ }^{4}$ Intriguingly, the Black Monday episode in October 1987 was characterized by high financial volatility but low financial stress, and no recession took place (a good outcome). Hence, the Black Monday potentially offers different information with respect to the one associated to the Great Recession (and, to some extent, COVID-19). Can the joint investigation of these two events - Black Monday and Great Recession - help us separately identify the role of uncertainty shocks and that of credit supply disruptions? If so, can we estimate the FUM for the US with aggregate time series data? Finally, can we take a stand on how costly an active FUM would be in COVID-19 times?

This paper addresses these questions via a time-series VAR analysis based on: i) state-of-the-art measures of financial uncertainty and stress, respectively estimated by Ludvigson, Ma, and Ng (2019) and Gilchrist and Zakrajšek (2012); ii) a rich set of restrictions designed to achieve set-identification, i.e., identification of models consistent with the data and in line with reasonable economic a-priori on the features of uncertainty and financial shocks in the scrutinized post-WWII US sample. ${ }^{5}$ We separate first and second-moment financial shocks by a novel mix of set-identification restrictions. In first place, we impose narrative restrictions based on events occurred in October 1987 and September 2008, months characterized - as stressed above - by a very different correlation between financial frictions and uncertainty. We require our structural VAR models to be associated to uncertainty (credit supply) shocks featuring high (low) values in correspondence of the Black Monday, and - contemporaneously - high (high) values in September 2008. These restrictions turn out to be very powerful in discarding models that do not well represent the 1987 and 2008 episodes. Then, we add further restrictions

\footnotetext{
${ }^{4} \mathrm{~A}$ detailed list of macroeconomic policy responses by the US (as well as a variety of other countries) can be found here: https://www.imf.org/en/Topics/imf-and-covid19/Policy-Responses-to-COVID-19

${ }^{5}$ Ludvigson et al.'s (2019) financial and macroeconomic uncertainty measures are based on the datarich approach developed by Jurado, Ludvigson, and Ng (2015), which models the common component of the time-varying variance of the forecast error of a large number of financial and macroeconomic series. Financial (macro) uncertainty is estimated as the common component of the time-varying volatility of the prediction errors of 148 financial (134 macroeconomic) series. Details on the estimation of these two factors are reported in Ludvigson, Ma, and $\mathrm{Ng}$ (2019).
} 
on the signs of our impulse responses to identify macroeconomic shocks, as well as correlations constraints involving external variables (à la Ludvigson, Ma, and Ng (2019)), and constraints on the signs of the ratios of the responses of uncertainty and EBP to first and second moment financial shocks (Furlanetto, Ravazzolo, and Sarferaz (2019)). ${ }^{6}$ All these restrictions, jointly imposed in our identification exercise, dramatically narrow the set of retained (admissible) models consistent with our economic a-priori.

Our retained models represent different interpretative models of the same data (the estimated covariance matrix of the VAR residuals). We then do three things with them. First, we produce impulse responses to a financial uncertainty shock. All models point to an increase in EBP and a decrease in real activity, the latter with peaks ranging from $-0.25 \%$ to $-0.85 \%$. We also find macroeconomic uncertainty to endogenously respond to macroeconomic shocks, something that financial uncertainty does not do. Second, we ask each of our retained models to indicate what would have happened to real activity after an uncertainty shock in a counterfactual world in which the response of EBP is muted. A dramatically milder response of industrial production arises in this scenario. Comparing the output response to the same financial uncertainty shock in presence of an endogenous vs. fixed EBP, we quantify the finance uncertainty multiplier to be in the order of 2, i.e., the endogenous response of EBP doubles the recession induced by the identified uncertainty shock. Third, we calibrate our VAR to simulate the effects of the March 2020 COVID-19 shock on financial uncertainty, and we ask our models to quantify the cumulative response of real activity over a one-year horizon. This exercise is conducted by designing two different scenarios, an "optimistic" one in which the only shock at work is the March 2020 unexpected uncertainty shock, and a "pessimistic" one which also considers an uncertainty shock in October 2020 (which is our way of modeling the consequences of a possible second wave of coronavirus infections). Our simulations indicate three things: i) the losses implied by our retained models in the two scenarios are relatively similar; ii) the cumulative output loss one year after the shock (captured by the response of industrial production in our VAR) could take values up to $31 \%$ in presence of an active FUM; iii) macroeconomic policies (in particular, liquidity injections) able to maintain financial stress at the pre-COVID-19 level could cut output losses by a large amount (between $1 / 4$ and $2 / 3$ of the overall loss).

The structure of the paper is the following. Section 2 discusses some related lit-

\footnotetext{
${ }^{6}$ Peersman (2005) introduced ratio restrictions to separately identify supply shocks and oil price shocks. In the paper, we refer to Furlanetto, Ravazzolo, and Sarferaz (2019) because of the similarity between their aim and ours, i.e., to disentangle first and second moment financial shocks.
} 
erature. Section 3 offers details on our empirical specification, with emphasis on our identification strategy. Section 4 documents our empirical results. Section 5 concludes.

\section{Related literature}

We connect to various contributions that have recently looked at the business cycle effects of uncertainty, financial frictions, and financial shocks. Caldara, Fuentes-Albero, Gilchrist, and Zakrajšek (2016) employ a linear VAR to study the macroeconomic effects of uncertainty shocks and those of first-moment financial shocks. They work with a penalty function approach which disentangles first and second moment financial disturbances based on their impact on the impulse responses of the corresponding financial proxies used in the VAR. They find uncertainty shocks to have an especially negative economic impact when they materialize in correspondence of a tightening of financial conditions. Lhuissier and Tripier (2016) and Alessandri and Mumtaz (2019) employ nonlinear VAR frameworks to deal with the uncertainty shocks-financial frictions interaction. They both find that uncertainty has larger negative effect on output in periods of financial distress than in tranquil times. We build on these contributions by working with informative restrictions for the identification of financial uncertainty shocks that do not require to deal with a recursive representation of the economic system. In this sense, our paper is close to the one by Furlanetto, Ravazzolo, and Sarferaz (2019), who identify financial and uncertainty shocks using a sign restrictions approach which features, among others, restrictions on ratios of proxies for first and second moment financial indicators. Our identification scheme borrows this idea from them, as well as event restrictions from Ludvigson, Ma, and Ng (2019). A related paper is Benati (2019), who is concerned with the role played by shocks to Baker et al.'s (2016) economic policy uncertainty (EPU) in driving the US, Canadian, UK, and Euro area business cycles. He finds that it is crucial to separately identify uncertainty and financial shocks for correctly quantify the real impact of the former ones. He then achieves separate identification of these two shocks by requiring the uncertainty (financial) shock to i) explain as much (little) as possible of the forecast error variance decomposition of EPU, and as little (much) as possible of that of EBP. He finds EPU shocks to have substantial effects on the US unemployment rate. Our contribution adds to all these papers by: i) providing a new set-identification approach to disentangle first and second moment financial shocks; ii) offering a quantification of the finance-uncertainty multiplier; iii) empirically assessing the impact of COVID-19-induced uncertainty shocks. The latter 
point is also taken up by Ludvigson, Ma, and $\mathrm{Ng}$ (2020), who work with a VAR featuring a novel series of costly disasters and study the impact of a multi-period COVID-19 shock on the US economy, and Leduc and Liu (2020) and Baker, Bloom, Davis, and Terry (2020), who work with VARs whose uncertainty shocks are calibrated to replicate the jump observed in financial and economic policy uncertainty when the pandemic hit the US as well as many industrialized countries in March 2020. With respect to them, our analysis differs under two main respects. First, our VAR also accounts for the response and impact of financial frictions on real activity, therefore considering the finance-uncertainty multiplier as a mechanism potentially at play during the pandemic. Second, we explicitly consider the possibility of a second wave hitting the US economy later in 2020, and quantify its impact under alternative scenarios.

From a theoretical standpoint, our paper offers support to microfounded DSGE models jointly modeling uncertainty shocks and financial frictions (Gilchrist, Sim, and Zakrajšek (2014), Christiano, Motto, and Rostagno (2014), Arellano, Bai, and Kehoe (2019), Alfaro, Bloom, and Lin (2019)). In particular, we share with Alfaro, Bloom, and Lin (2019) the goal of quantifying the FUM. Alfaro, Bloom, and Lin (2019) first provide empirical evidence on the FUM by working with micro-data related to US publiclylisted firms. They find that financial frictions amplify the real impact of uncertainty shocks, with a multiplier as large as 3 during the Great Recession. Then, they build a microfounded framework where firms face a fixed cost of investment, and where raising external funds is costly too. The model is shown to replicate their main empirical facts, with a multiplier as large as 2. Our VAR estimates also point to a FUM of about 2 (median value), i.e., they suggest a drop in output due to an uncertainty shock twice as large in presence of financial frictions than in a frictionless world. Moreover, some of our models point to values of the FUM as large as 3. Our results, which are fully in line with Alfaro et al.'s (2019), are obtained with a completely different empirical strategy (simulations with a micro-founded DSGE framework calibrated with micro-data in their case, time-series analysis with macro data in ours).

\section{Empirical approach}

Data and VAR specification. We estimate the following reduced-form VAR model on monthly US data, sample: July 1973-December 2019: ${ }^{7}$

\footnotetext{
${ }^{7}$ At the time of writing, LMN financial uncertainty measure is available until April 2020. We decided to use data for estimation up to December 2019, and not April 2020, because the recession caused by
} 


$$
\mathbf{X}_{t}=\sum_{j=1}^{p} \mathbf{A}_{j} \mathbf{X}_{t-j}+\boldsymbol{\eta}_{t}, \quad \boldsymbol{\eta}_{t} \sim(0, \boldsymbol{\Omega})
$$

where $\mathbf{A}_{j}$ are matrices of coefficients, $\boldsymbol{\eta}_{t}$ is the vector of error terms whose variancecovariance is $\Omega$, and $\boldsymbol{\Omega}=\boldsymbol{P} \boldsymbol{P}^{\prime}$, where $\boldsymbol{P}$ is the unique lower-triangular Cholesky factor with non-negative diagonal elements. The VAR features equation-specific constants and linear trends. We model the four-variable vector $\mathbf{X}_{t}=\left[U_{t}^{m}, 100 \log \left(I P_{t}\right), U_{t}^{f}, E B P_{t}\right]^{\prime}$, where $U_{t}^{m}$ and $U_{t}^{f}$ are, respectively, the macroeconomic and financial uncertainty proxies constructed by Ludvigson, Ma, and $\mathrm{Ng}(2019) ;{ }^{8} I P_{t}$ stands for industrial production; ${ }^{9}$ and $E B P_{t}$ is the excess bond premium measure proposed by Gilchrist and Zakrajšek (2012) and regularly updated by Favara, Gilchrist, Lewis, and Zakrajšek (2016). Among all available proxies of uncertainty, we decided to use Ludvigson et al.'s (2019) uncertainty indices for three reasons. First, they provide different measures for macro and financial uncertainty constructed in a similar way, so that any differences in their behavior cannot be attributed to a different measurement approach. This is important because, as stressed in Ludvigson, Ma, and $\mathrm{Ng}$ (2019), the response of macroeconomic uncertainty to financial uncertainty shocks is crucial in correctly quantifying the magnitude and the persistence of the real activity contraction triggered by heightened uncertainty. This is why, even though we are not directly interested in identifying macro uncertainty shocks, we include macroeconomic uncertainty in our VAR. Second, they have a forward looking nature, as they capture the uncertainty about current outcomes given the information set available today. Third, they are considered state-of-the-art measures and have become highly popular in the uncertainty literature. ${ }^{10}$

the COVID-19 outbreak is still unfolding, and data of a full cycle are not available yet.

${ }^{8}$ The uncertainty indices are extracted from large datasets, one mostly featuring macro series, the other financial ones. Ludvigson, Ma, and Ng (2019b) perform a forecasting exercise for each variable with an autoregressive model, with forecast errors allowed to feature a time-varying volatility process. The uncertainty indices are then computed using a factor model of such conditional volatilities.

${ }^{9}$ We model IP in log-levels (as opposed to log-differences) for two reasons. First, this choice enhances the comparability of our results with Ludvigson et al.'s (2019), who also model industrial production in log-levels. Second, tests on the degree of integration of a trending variable have relatively low power in presence of local to unity variables, and industrial production is one of them (see Stock (1991) and Abadir, Caggiano, and Talmain (2013), among others). Following Canova (2007), we interpret the stationarity of the residuals in the industrial production equation as a sign in favor of our model's ability to model its trending behavior. Third, modeling industrial production in first differences would open the door to the possibility of a permanent effect on the level of output of the transitory uncertainty shock we focus on in this study. This would be inconsistent with Alfaro et al.'s (2019) model, which does not allow for such permanent effects.

${ }^{10}$ Figure 1 plots the VXO as a measure of financial uncertainty. When looking at the dynamics around the COVID-19 outbreak, we prefer to use the VXO instead of Ludvigson et al.'s (2019) financial uncertainty for two reasons. First, the VXO is available daily, and as such allows us to track any current 
Identification. We move from the reduced-form VAR (1) to the structural one as follows. First, we assume that the system of contemporaneous relationships mapping reduced form residuals $\boldsymbol{\eta}_{t}$ and structural shocks $\mathbf{e}_{t}$ can be described as

$$
\boldsymbol{\eta}_{t}=\boldsymbol{B} \mathbf{e}_{t}, \quad \mathbf{e}_{t} \sim\left(0, \boldsymbol{I}_{\boldsymbol{n}}\right)
$$

where $\boldsymbol{B}$ is a matrix featuring $n^{2}$ elements. Given that the reduced form covariance matrix $\Omega$ features only $n(n+1) / 2$ restrictions, further restrictions have to be imposed to identify the effects of the structural shocks $\mathbf{e}_{t}$ on the endogenous variables $\mathbf{X}_{t}$. Without such further restrictions, infinitely many solutions satisfy the covariance restrictions $\Omega=\boldsymbol{B} \boldsymbol{B}^{\prime}$. We collect $K=5$ millions of these solutions into the set $\mathcal{B}=\left\{\boldsymbol{B}=\boldsymbol{P} \boldsymbol{Q}: \boldsymbol{Q} \in \mathcal{O}_{\underline{n}}, \operatorname{diag}(\boldsymbol{B}) \geqslant 0, \boldsymbol{\Omega}=\boldsymbol{B} \boldsymbol{B}^{\prime}\right\}$, where $\mathcal{O}_{\underline{n}}$ is a set of orthonormal matrices (i.e., $\boldsymbol{Q} \boldsymbol{Q}^{\prime}=\boldsymbol{I}_{\boldsymbol{n}}$ ). The set $\mathcal{B}$ is constructed by implementing the algorithm proposed by Rubio-Ramírez, Waggoner, and Zha (2010). We rotate $\boldsymbol{B}$ by drawing one $K$ random orthogonal matrices $\boldsymbol{Q}$. Each rotation is performed by drawing a matrix $\boldsymbol{M}$ from a multivariate normal $\mathcal{N}\left(\mathbf{0}, \boldsymbol{I}_{\boldsymbol{n}}\right)$ density. Then, $\boldsymbol{Q}$ is taken to be the orthonormal matrix in the $\boldsymbol{Q R}$ decomposition of $\boldsymbol{M}$. Given that $\boldsymbol{B}=\boldsymbol{P} \boldsymbol{Q}$ and $\boldsymbol{Q} \boldsymbol{Q}^{\prime}=\boldsymbol{I}_{\boldsymbol{n}}$, the covariance restrictions $\boldsymbol{\Omega}=\boldsymbol{B} \boldsymbol{B}^{\prime}$ are satisfied. Let $\mathbf{e}_{t}(\boldsymbol{B})=\boldsymbol{B}^{-1} \boldsymbol{\eta}_{t}$ be the shocks implied by $\boldsymbol{B} \in \mathcal{B}$ for a given $\boldsymbol{\eta}_{t}$. Then, $K$ different $\boldsymbol{B}$ imply $K$ unconstrained $\mathbf{e}_{t}(\boldsymbol{B})=\boldsymbol{B}^{-1} \boldsymbol{\eta}_{t}$, $t=1, \ldots, T$.

While the set $\mathcal{B}$ contains solutions mathematically coherent with equations (1)-(2), not all these solutions are equally interesting from an economic standpoint. We aim at identifying the set of economically admissible solutions $\overline{\mathcal{B}}$ (conditional on our research question) by imposing different types of identification restrictions, i.e., event constraints, external variable constraints, and sign restrictions.

Event constraints. Event constraints are constraints imposed directly on the shocks $\mathbf{e}_{t}(\boldsymbol{B})$ (Antolín-Díaz and Rubio-Ramírez (2019), Ludvigson, Ma, and Ng (2019)). We identify uncertainty shocks by focusing on two months in which financial volatility hit record-high levels, i.e., October 1987 (Black Monday) and September 2008 (Lehman Brothers' collapse and acceleration of the global financial crisis). For a model $\boldsymbol{B}$ to belong to the set of admissible solutions, we require financial uncertainty shocks implied

developments in financial uncertainty due to the ongoing COVID-19 outbreak in real time, while LMN is available on a monthly frequency and is released with delays. Second, at the time of writing this version, EBP is available until May 2020, while LMN until April. Plotting the LMN index would allow us to track the dynamics of financial uncertainty and financial stress that followed the peak reached in March 2020 for one month only. It is also worth mentioning that the correlation between Ludvigson et al.'s (2019) financial uncertainty index and the VXO is positive and large (equal to 0.83). Our Appendix documents the comovement of these two financial volatility series. 
by such model in these two months to be larger than the 65 th percentile of $p(\mathcal{B})$, i.e., the empirical density conditional on all unconstrained solutions $\mathcal{B}$ (again, in the two months of interest). The idea is that such large jumps may be mostly exogenous and, therefore, associated to GFU shocks. As anticipated in the Introduction, we separate first and second moment financial shocks by requiring that the same $\boldsymbol{B}$ generate shocks to EBP which are also large in September 2008 (larger than the 65th percentile of the empirical density conditional on all unconstrained solutions $\mathcal{B}$ ), but small (below the median of $p(\mathcal{B}))$ in October 1987. Figure 2 corroborates this way to proceed. Such Figure plots the empirical density $p(\mathcal{B})$ for the uncertainty and EBP shocks conditional on October 1987 and September 2008. The similarities between these two densities during the Great Recession are evident - in particular, they are both heavily left skewed. This is consistent with Lehman Brothers' bankruptcy as an event injecting uncertainty and freezing the credit market. Quite differently, the Black Monday episode in October 1987 is characterized by a left skewed distribution of uncertainty shocks, but a right skewed one for credit supply shocks. Importantly, the difference in these two empirical densities is not driven by any modeling assumption (apart from those related to the reducedform VAR, i.e., variables modeled here, number of lags, etc.). Hence, our identification strategy exploits "genuine" differences between the densities of the financial uncertainty and EBP shocks in 1987, and their similarities in 2008.

We also impose event restrictions to identify macro uncertainty shocks and output shocks. This is done in an attempt to separate these shocks from uncertainty shocks, therefore sharpening the identification of the latter. Following the same definition adopted above for financial shocks, we require macroeconomic uncertainty shocks to be large in October 2008. Turning to output shocks and event constraints, we follow Ludvigson, Ma, and $\mathrm{Ng}$ (2019) and require that the sum of the realizations of the output shocks during the December 2007-June 2009 (US recession according to the NBER) be negative.

Correlation constraints. Ludvigson, Ma, and Ng (2019) impose correlations between uncertainty shocks and external variables on the basis that such correlations are predicted by a variety of macro-finance DSGE frameworks. Following their lead, we impose a negative correlation (smaller than -0.1) between uncertainty shocks and stock market returns, and we do the same for EBP shocks. ${ }^{11}$

IRF-related constraints. We further sharpen the identification of our financial uncertainty shocks by imposing two different types of sign restrictions on the impulse

\footnotetext{
${ }^{11}$ Stock market returns are based on the SP500 stock market index.
} 
responses $\operatorname{IRF}(\boldsymbol{B}, \mathbf{A} j)$. First, we require a jump in our financial indicators to be associated with an economic downturn. This prediction is based on a long list of empirical contributions (see Gilchrist and Zakrajšek (2012) for the EBP shock, and Bloom (2014) and Castelnuovo (2019) for surveys collecting contributions that document the recessionary effects of spikes in uncertainty). Going back to the challenge of separating first and second moment financial shocks, we follow the approach proposed by Furlanetto, Ravazzolo, and Sarferaz (2019) and impose restrictions on the ratios of the impulse responses of financial uncertainty and EBP. In particular, we impose that a financial uncertainty (EBP) shock generate an on-impact response of the financial uncertaintyEBP ratio bigger (smaller) than one. ${ }^{12}$

The set of constraints imposed in our analysis is collected in Table 1. The joint imposition of the above described constraints on the set of unconstrained models $\mathcal{B}$ delivers a set of 56 admissible solutions $\overline{\mathcal{B}}$, which we employ to study the macroeconomic effects of financial uncertainty shocks. ${ }^{13}$ Identification uncertainty is worth a discussion. ${ }^{14}$ The sole imposition of the restrictions related to the Black Monday leads us to retain just $13.1 \%$ of the models; that of the Great Recession to identify financial shocks to retain $9.4 \%$ of the models; the joint imposition of restrictions related to the Black Monday and Great Recession events for the identification of first and second-moment financial uncertainty to retain $1.4 \%$ of the models. Clearly, the implications of the different correlation between financial uncertainty and EBP are pretty informative as far as our model selection exercise is concerned. Turning to the real side of the economy, if we only impose restrictions to identify macroeconomic uncertainty shocks and output shocks, we end up discarding about $80.5 \%$ of the models. Instead, if we only impose standard sign restrictions on the impulse responses (to variables in levels), we retain just $2.4 \%$ of the models. When also adding the sign restrictions to the ratios of the impulse responses, the share of retained models further drop to $0.5 \%$. When all these

\footnotetext{
${ }^{12}$ Caldara, Fuentes-Albero, Gilchrist, and Zakrajšek (2016) separate first and second moment shocks by appealing to a penalty function identification strategy which relies on the ordering of the two first and second moment proxies in the vector. The advantage of the identification restriction pursued here is that it does not require to assume a recursive economy.

${ }^{13}$ We see the fact that our identifying constraints select 56 models out of 5 millions as a good sign. This is in line with Uhlig's (2017) Principle 7: "When a lot of draws are rejected, the identification is sharp. Good!". However, Baumeister and Hamilton (2019) point out that, when just a few models survive out of a large number of draws, an element unrelated to economic considerations such as the seed one sets for running simulations can actually be a crucial driver of the simulation results. Our Appendix documents that our results are robust to the setting of different seeds.

${ }^{14}$ The term "identification uncertainty" was coined by Giorgio Primiceri in the context of Ludvigson et al.'s (2019) analysis.
} 
restrictions are jointly imposed, we retain just $0.00112 \%$ of the models (56 models out of 5 millions). (When the 1987 restrictions only are dropped from the set of restrictions, the number of retained models is five times larger, i.e., 255.) Wrapping up, we can state that: i) event restrictions combining information related to the Black Monday and the Great Recession turn out to be extremely informative to separately identify first and second-moment financial shocks; ii) when all our restrictions are jointly imposed, a share larger than $99 \%$ of the models consistent with the data is discarded. This evidence is telling on the power of our restrictions to identify the shocks triggering the dynamics of our observables, financial uncertainty shock in first place. Reassuringly, our identified shocks are positively correlated with the uncertainty and industrial production shocks identified by Ludvigson, Ma, and Ng (2019). Our Appendix shows such a positive correlation between their shocks and our shocks conditional on: i) focusing on the representative "maxG" model only; ii) across all models we retain (with respect to Ludvigson et al's "maxG" model). All correlations are documented to be high. In particular, the correlations between the financial uncertainty shocks consistent with our 56 retained models and the financial uncertainty shock conditional on the representative "maxG" model by Ludvigson, Ma, and Ng (2019) ranges from 0.75 to 0.98.

\section{Empirical Findings}

Impulse responses. Figure 3 plots the impulse responses to a financial uncertainty shock (size: one standard deviation) and to the other shocks identified in our VAR. Following an exogenous jump in financial uncertainty, industrial production temporarily contracts, with a peak response across models ranging between $-0.25 \%$ and $-0.85 \%$, before gradually going back to trend. EBP increases, tops at about 10 basis points, then gradually goes back to the pre-shock level. While these responses do not necessarily point to the existence of the FUM, they are consistent with it - we elaborate on this point below. Interestingly, all models point to an increase in macroeconomic uncertainty in the short-run. Differently, the response of financial uncertainty to a macroeconomic uncertainty shock is not common across models, with some models pointing to a positive one and other to a negative reaction. Another difference between these two concepts of uncertainty emerges when looking at their responses to an output shock - the retained models are inconclusive when it comes to financial uncertainty, while they all point to a negative short-run response of macroeconomic uncertainty. This evidence is consistent with the findings in Ludvigson, Ma, and Ng (2019), who identify financial uncertainty 
as a driver of the business cycle, and macroeconomic uncertainty as a consequence of movements in output (for related evidence, see Angelini, Bacchiocchi, Caggiano, and Fanelli (2019)). Finally, we confirm the findings in Gilchrist and Zakrajšek (2012), i.e., a jump in EBP is followed by a temporary contraction in output. Interestingly, it is also followed by a short-run increase in financial uncertainty. This last result, coupled with the one on the response of EBP to an uncertainty shock, corroborates our choice of using an identification scheme alternative to the Cholesky decomposition of the covariance matrix of the estimated residuals to identify financial uncertainty shocks when measure of financial stress belong to the VAR.

Finance-uncertainty multiplier. Armed with our estimated VAR and our 56 retained models, we then compute the finance-uncertainty multipliers implied by each model. Conceptually, the finance-uncertainty multipliers capture the different effect on output of an uncertainty shock, with and without endogenous financial frictions. Our VAR analysis has so far proposed the "factual" scenario, i.e., the response of real activity with financial frictions, i.e. with EBP left free to react after the uncertainty shock. To obtain the "counter-factual" scenario, i.e., the response of real activity in absence of financial frictions (i.e. with EBP which remains fixed to the pre-uncertainty shock level), we re-compute our impulse responses by shutting down the response of EBP to the uncertainty shock.

Per each model $\boldsymbol{B}$ and horizon $h$, we then compute the implied FUM as the following ratio:

$$
F U M(\boldsymbol{B}, h)=\frac{\min \left[\frac{\partial 100 \log \left(I P_{t+h}\right)}{\partial e_{t}^{U^{f}}}(\boldsymbol{B})\right]}{\min \left[\frac{\partial 100 \log \left(I P_{t+h}\right)}{\partial e_{t}^{U^{f}}}(\boldsymbol{B}) \mid \frac{\partial E B P_{t+h}}{\partial e_{t}^{U f}}(\boldsymbol{B})=0\right]}, h=0, \ldots, H
$$

where the numerator is the minimum value (i.e., the largest negative realization) of industrial production to an uncertainty shock when the response of EBP is unconstrained, the denominator is the minimum value of the response of industrial production to an uncertainty shock when the response of EBP is kept fixed. ${ }^{15}$

Figure 4 depicts the empirical density of the FUM conditional on our 56 models. The median value of such density reads 2.04 , i.e., financial frictions are found to double the negative effects on output of hikes in financial uncertainty. There is dispersion across

\footnotetext{
${ }^{15}$ Purposely, the minimum realizations of the response of industrial production at the numerator vs. denominator in the $F U M(\boldsymbol{B}, h)$ expression need not realize at the very same horizon $h$. This because there is no theoretical reason to believe that the two minimum values should materialize after an equal number of periods. This is exactly one of the points made by Alfaro, Bloom, and Lin (2019), i.e., financial frictions affect the shape and persistence via which output responds to an uncertainty shock.
} 
the 56 multipliers we compute, with a minimum value equal to 1.56 and a maximum equal to 3.31. As stated in previous parts of the paper, this finding - obtained with a VAR analysis based on aggregate time series - provides an indication qualitatively and quantitatively in line with that of Alfaro, Bloom, and Lin (2019), who work with a calibrated micro-founded DSGE framework featuring real option effects and financial frictions. They also find a FUM equal to 2 on average, and 3 in an extraordinary event like the Great Recession. Our Appendix documents the robustness of our empirical findings to a different definition of the multiplier based on the cumulative, rather than the peak, response of industrial production, obtained by calculating the integral of the factual and counterfactual responses of industrial production to an uncertainty shock over a 2-year horizon. Our baseline results on the amplification of the real effects of uncertainty shocks due to financial frictions are confirmed, with a median multiplier close to 2.2 and a maximum multiplier as large as 5.9.

COVID-19 shock. As documented in the Introduction, the COVID-19 pandemic has injected an enormous amount of uncertainty in the US economic system as well as in most economies around the world. While financial markets seem to have partly recovered by such a negative shock, the level of uncertainty surrounding the future dynamics of the coronavirus remains high. Bayesian panel forecasts of country-level COVID-19 infections are characterized by pretty wide credible sets (Liu, Moon, and Schorfheide (2020)); consistently, medical experts such as Anthony Fauci and Nicholas Christakis predict a second wave to come sometime in Fall; ${ }^{16}$ and leading economists warn against a reopening that may lead to a severe second wave of deaths and, consequently, to a second shutdown, the risks being that of a long-lasting damage due to the difficulty to replicate the level of support by fiscal and monetary policy makers which has so far limited the economic damage (see, e.g., Stock (2020)). One implication of this level of support is exactly the liquidity injected in the economic system by the Federal Reserve, which has worked against an increase in EBP as large as the one observed during the Great Recession. According to our analysis so far, these interventions have at least partially sheltered the economy from the contractionary impact of uncertainty shocks by keeping, by and large, credit disruptions at bay, and hence by minimizing the finance-uncertainty multiplier.

But what if the FUM had to be back in full swing? ${ }^{17}$ We then use our VAR to

\footnotetext{
${ }^{16}$ Information available, respectively, at https://edition.cnn.com/2020/04/29/health/us-coronavirus-wednesday/index.html , and https://edhub.ama-assn.org/jn-learning/audio-player/18393767 (around 25').

${ }^{17}$ For an updated analysis on the weak spots of the global financial markets, which include sources
} 
estimate the economic costs of the uncertainty-induced COVID-19 shock by working with two different scenarios: an "optimistic" one, in which the unexpected jump in uncertainty occurred in March 2020 is not followed by any subsequent shock; and a "pessimistic" one, in which a second wave of deaths dramatically hits the US in Fall 2020, getting uncertainty back to pretty high levels. For each of these scenarios, we compute the cumulative industrial production loss during the period March 2020-February 2021, i.e., one year after the unexpected COVID-19-induced uncertainty shock, and we contrast it with the loss we would observe without an active FUM. The goals of these exercise are: i) quantify the overall short-run loss in industrial production under different uncertainty profiles; ii) assess the quantitative relevance of policy interventions aimed at guaranteeing liquidity to the private sector in the aftermath of the unexpected COVID-19 shock.

We construct our scenarios as follows. First, for both of them, we calibrate the size of the COVID-19-induced unexpected uncertainty shock in March 2020 by looking at the difference between the value of the VIX at its peak in mid March 2020 (on March 16, the VIX reached its record high level, jumping at 82.69) and its value exactly one month before, on February 16, 2020. The choice of the time span for computing the increase in the VIX is due to the monthly frequency of the data we model in this study. This gives us a scale factor equal to 5.6. Following Baker, Bloom, Davis, Kost, Sammon, and Viratyosin (2020), we then attribute $90 \%$ of the jump in the VXO in that month to COVID-19, which implies a scaling factor equal to 5.6 x $0.9=5.04 .^{18}$ The "optimistic" scenario - which considers the March 2020 unexpected shock only - is then implemented by applying this scaling factor to the cumulated impulse responses of output behind our FUM depicted in Figure 4. The "pessimistic" scenario is instead built up by also considering - on top of the unexpected shock in March 2020 - a future uncertainty shock seven period after the March 2020 one. In other words, we consider another uncertainty shock in October 2020, which is meant to capture the financial turmoil that might emerge in the event of a second wave in Fall. We assume such future shock to generate $75 \%$ of the volatility induced by the unexpected one in March 2020. This calibration is related to the $75 \%$ probability of a second wave of COVID-19 in Fall 2020 stated by Nicholas Christakis in an interview to the Journal of American

of financial fragilities affecting the US economy, see Adrian and Natalucci (2020).

${ }^{18}$ Baker, Bloom, Davis, Kost, Sammon, and Viratyosin (2020) look at the measure of economic policy uncertainty (EPU) developed by Baker, Bloom, and Davis (2016) and calculate the proportion of newspapers articles that, in March 2020, mentioned COVID-19 along with the other keywords used to calculate the EPU index. They find that COVID-19 was mentioned in at least $90 \%$ of articles. 
Medical Association on April 1, 2020. ${ }^{19}$

Figure 5 plots the histograms of the losses related to these scenarios. Our models predict quite an ample dispersion of output losses. Quite interestingly, the maximum losses are relatively close in spite of the different profiles of spikes in uncertainty characterizing the different scenarios, with the one in the optimistic (pessimistic) one reading $27 \%$ (31\%). Differently, the minimum losses are more dissimilar, with the one in the optimistic scenario reading $-3 \%$ vs. $-9 \%$ in the pessimistic one. Table 2 collects the key figures of these simulations. The contrast of the cumulative losses when EBP is endogenous and allowed to respond to spikes in financial uncertainty vs. when it is fixed (our proxy for a world without credit constraints) points to a potentially large role that monetary policy authorities can play in weathering the storm even in face of a large uncertainty shock such as the COVID-19 one. In the worst case scenario, in fact, the maximum loss under the "EBP kept fixed" scenario is about $24.2 \%$, i.e., $25 \%$ lower than the loss which would occur, according to our model, if the finance-uncertainty multiplier were left free to kick in after the realization of the uncertainty shock. Turning to the most moderate loss in the very same pessimistic scenario, we have about $10 \%$ if EBP is endogenous vs. $3.4 \%$ if EBP is kept at the pre-uncertainty shock level, i.e., $2 / 3$ of the cumulative loss could be avoided by maintaining the flow of credit to the private sector as healthy as before the shock.

\section{Conclusions}

This paper documents the presence of a finance uncertainty multiplier (which is, an amplification of the real effects of uncertainty shocks due to financial frictions) for the US economy. We do so by conducting a VAR analysis and appealing to a novel combination of event, correlation, and sign restrictions to separately identify financial uncertainty and credit supply shocks. Our reference estimate of the finance uncertainty multiplier is 2, i.e., the presence of financial frictions doubles the response of real activity to an uncertainty shock. Simulations conducted with our estimated VAR point to a cumulative output loss (proxied by industrial production) as large as $31 \%$ over one year. Our model suggests that liquidity interventions aiming at keeping credit conditions as healthy as they were before the COVID-19 uncertainty shock could cut such loss by a substantial amount, ranging from one fourth to two thirds. Our results offer support to the rapid and massive liquidity interventions engineered by the Federal Reserve to

\footnotetext{
${ }^{19}$ https://edhub.ama-assn.org/jn-learning/audio-player/18393767 (around 25').
} 
avoid the disruption of the credit markets in the United States after the advent of the pandemic.

\section{References}

Abadir, K., G. Caggiano, and G. Talmain (2013): "Nelson-Plosser revisited: the ACF approach," Journal of Econometrics, 175, 22-34.

Adrian, T., and F. Natalucci (2020): "Global Financial Stability Report: Markets in the Time of COVID-19," International Monetary Fund, April.

Alessandri, P., and H. Mumtaz (2019): "Financial Regimes and Uncertainty Shocks," Journal of Monetary Economics, 101, 31-46.

Alfaro, I., N. Bloom, and X. Lin (2019): "The Finance Uncertainty Multiplier," available at https://nbloom.people.stanford.edu/research.

Angelini, G., E. Bacchiocchi, G. Caggiano, and L. Fanelli (2019): "Uncertainty Across Volatility Regimes," Journal of Applied Econometrics, 34(3), 437-455.

Antolín-Díaz, J., and J. F. Rubio-Ramírez (2019): "Narrative Sign Restrictions," American Economic Review, forthcoming.

Arellano, C., Y. Bai, And P. J. Kehoe (2019): "Financial Markets and Fluctuation in Volatility," Journal of Political Economy, forthcoming.

Baker, S., N. Bloom, and S. J. Davis (2016): "Measuring Economic Policy Uncertainty," Quarterly Journal of Economics, 131(4), 1539-1636.

Baker, S., N. Bloom, S. J. Davis, and S. J. Terry (2020): "COVID-Induced Economic Uncertainty," available at https://nbloom.people.stanford.edu/.

Baker, S. R., N. Bloom, S. J. Davis, K. Kost, M. Sammon, and T. Viratyosin (2020): "The Unprecedented Stock Market Reaction to COVID-19," available at https://nbloom.people.stanford.edu/research.

BAsu, S., And B. Bundick (2017): "Uncertainty Shocks in a Model of Effective Demand," Econometrica, 85(3), 937-958.

Baumeister, C., And J. D. Hamilton (2019): "Structural Interpretation of Vector Autoregressions with Incomplete Identification: Setting the Record Straight," available at https://sites.google.com/site/cjsbaumeister/research.

Benati, L. (2019): "Economic Policy Uncertainty, the Great Recession, and the Great Depression," University of Bern, mimeo.

Bloom, N. (2014): "Fluctuations in Uncertainty," Journal of Economic Perspectives, $28(2), 153-176$.

Caldara, D., C. Fuentes-Albero, S. Gilchrist, and E. Zakrajšek (2016): "The Macroeconomic Impact of Financial and Uncertainty Shocks," European Economic Review, 88, 185-207. 
Canova, F. (2007): Methods for Applied Macroeconomic Research, Princeton University Press, Princeton, New Jersey.

Castelnuovo, E. (2019): "Domestic and Global Uncertainty: A Brief Survey and Some New Results," CESifo Working Paper No. 7900.

Christiano, L., R. Motto, and M. Rostagno (2014): "Risk Shocks," American Economic Review, 104(1), 27-65.

Favara, G., S. Gilchrist, K. F. Lewis, and E. ZakrajŠEK (2016): "Updating the Recession Risk and the Excess Bond Premium," FEDS Notes. Washington: Board of Governors of the Federal Reserve System.

Furlanetto, F., F. Ravazzolo, and S. Sarferaz (2019): "Identification of financial factors in economic fluctuations," Economic Journal, 129, 311-337.

Gertler, M., and S. Gilchrist (2017): "What Happened: Financial Factors in the Great Recession," Journal of Economic Perspectives, forthcoming.

Gilchrist, S., J. W. Sim, and E. ZakrajŠEk (2014): "Uncertainty, Financial Frictions, and Investment Dynamics," Boston University and Federal Reserve Board of Governors, mimeo.

Gilchrist, S., And E. ZakrajŠEk (2012): "Credit Spreads and Business Cycle Fluctuations," American Economic Review, 102(4), 1692-1720.

Jurado, K., S. C. Ludvigson, And S. NG (2015): "Measuring Uncertainty," American Economic Review, 105(3), 1177-1216.

Leduc, S., AND Z. Liu (2020): "The Uncertainty Channel of the Coronavirus," Federal Reserve Bank of San Francisco Economic Letter No. 2020-07.

Lhuissier, S., And F. TRIPIER (2016): "Do Uncertainty Shocks Always Matter for Business Cycles?," CEPII Working Paper No. No 2016-19.

Liu, L., H. R. Moon, And F. Schorfheide (2020): "Panel Forecasts of CountryLevel Covid-19 Infections," available at https://web.sas.upenn.edu/schorf/.

Ludvigson, S. C., S. Ma, and S. NG (2019): "Uncertainty and Business Cycles: Exogenous Impulse or Endogenous Response?," American Economic Journal: Macroeconomics, forthcoming.

(2020): "COVID19 and The Macroeconomic Effects of Costly Disasters," available at https://www.sydneyludvigson.com/working-papers.

Peersman, G. (2005): "What Caused the Early Millennium Slowdown? Evidence Based on Vector Autoregressions," Journal of Applied Econometrics, 20, 185-207.

Pellegrino, G., G. Caggiano, and E. Castelnuovo (2019): "Uncertainty, Real Activity, and Risk Aversion during the Great Recession," Aarhus University, Monash University, and University of Melbourne, in progress.

Rubio-Ramírez, J. F., D. F. Waggoner, and T. Zha (2010): "Structural Vector Autoregressions: Theory of Identification and Algorithms for Inference," Review of Economic Studies, 77, 665-696. 
Stock, J. H. (1991): "Confidence Intervals for the Largest Autoregressive Root in Macroeconomic Time Series," Journal of Monetary Economics, 28, 435-459.

(2020): "Reopening the Coronavirus-Closed Economy," Hutchins Center Working Paper No. 60.

Stock, J. H., And M. W. Watson (2012): "Disentangling the Channels of the 20072009 Recession," Brookings Papers on Economic Activity, Spring, 81-135.

Uhlig, H. (2017): "Shocks, Sign Restrictions, and Identification," in Bo Honoré, Ariel Pakes, Monika Piazzesi, and Larry Samuelson (eds): Advances in Economics and Econometrics, Vol. 1 and 2: Eleventh World Congress, Chapter 4, Cambridge University Press, Cambridge. 


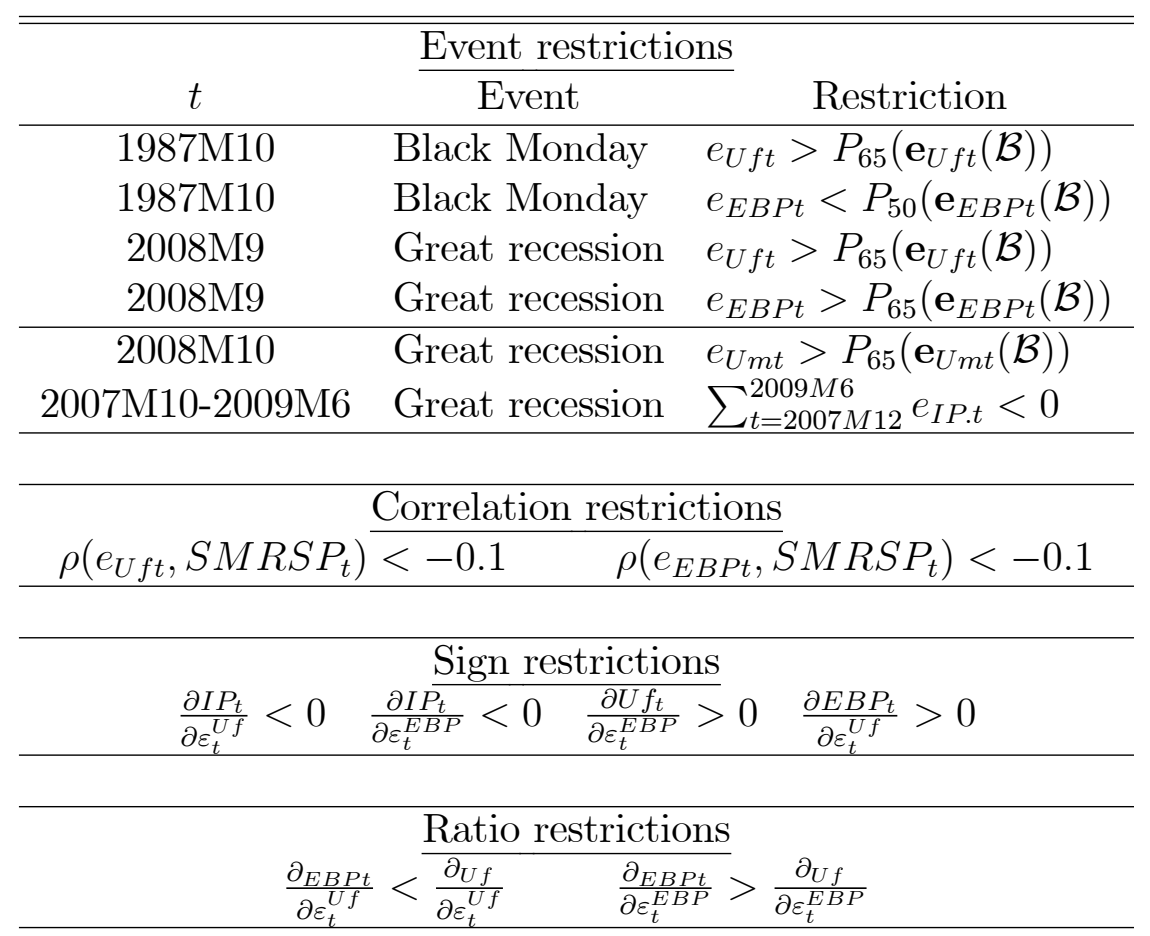

Table 1: Identification restrictions. Constraints imposed to separately identify financial uncertainty and excess bond premium shocks. Uf stands for financial uncertainty; EBP for excess bond premium; Um for macroeconomic uncertainty; SMRSP for SP500 stock market returns; IP for industrial production.

\begin{tabular}{cccc}
\hline \hline Output loss & EBP endogenous & EBP fixed & Loss reduction \\
\hline Min loss & $9.8 \%$ & $3.4 \%$ & $2 / 3$ \\
Max loss & $31 \%$ & $24.2 \%$ & $1 / 4$ \\
\hline
\end{tabular}

Table 2: Output loss reduction in absence of financial frictions. Figures related to the pessimistic scenario, which features an uncertainty shock in March 2020 and one in October 2020. Details on the calibration of the shocks are available in the text. 


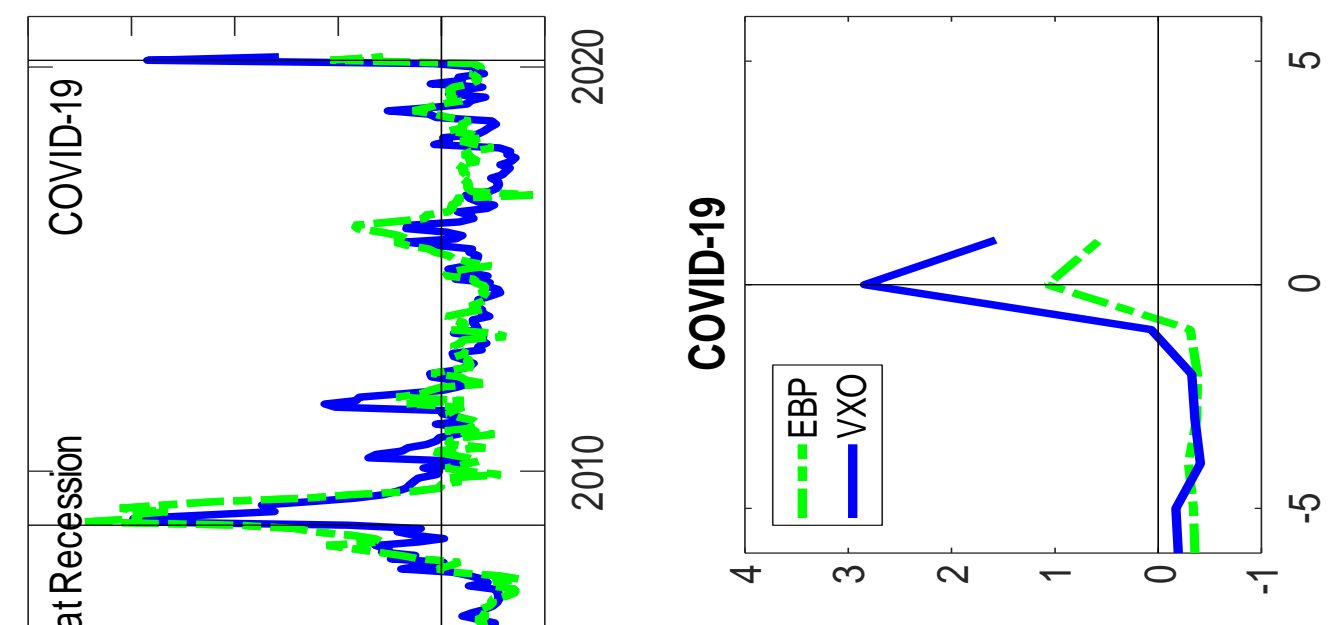

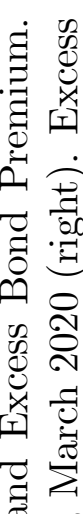

○ิ

$>$.

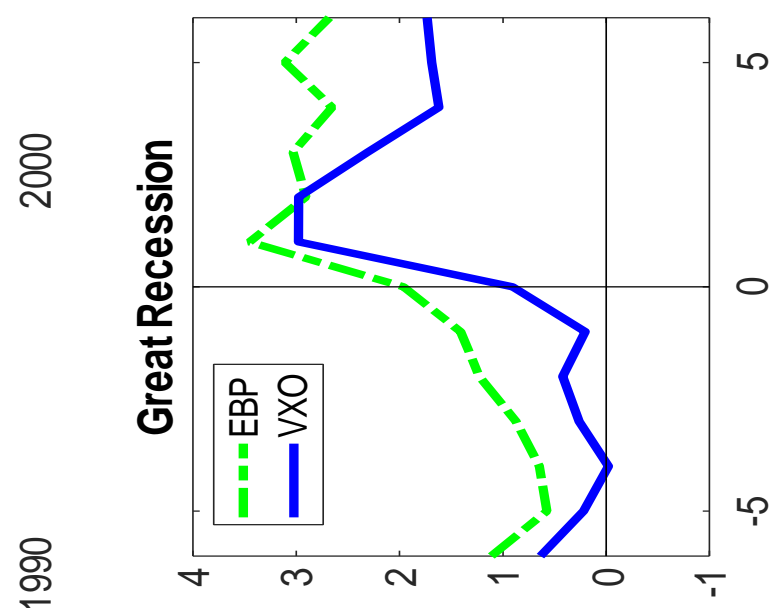

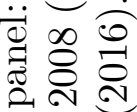

응 ठี่

द्वै

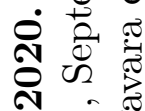

N

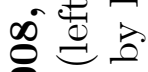

ণิ

N

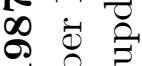

$\rightarrow$ 응

.‡

궙 ฮิ

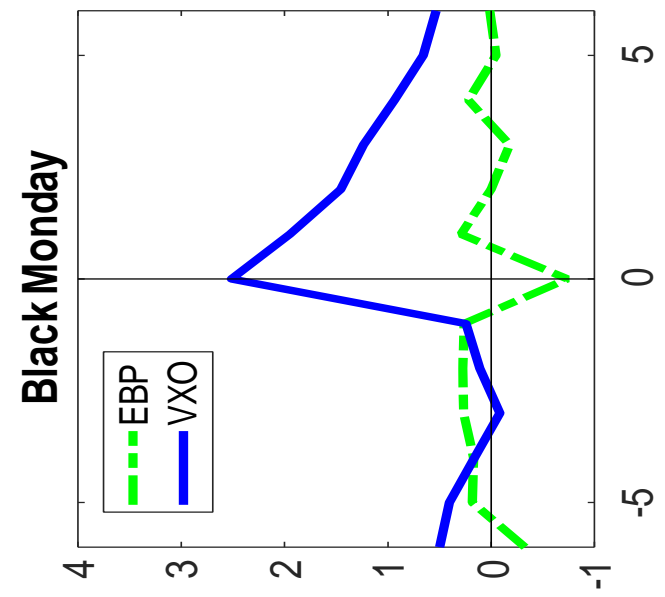

票

넌

ن류.

$\supset N$

ซ్

की की

㟧至兽

శత్ర

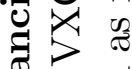

过芯

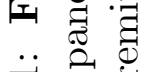

$-1$

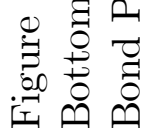



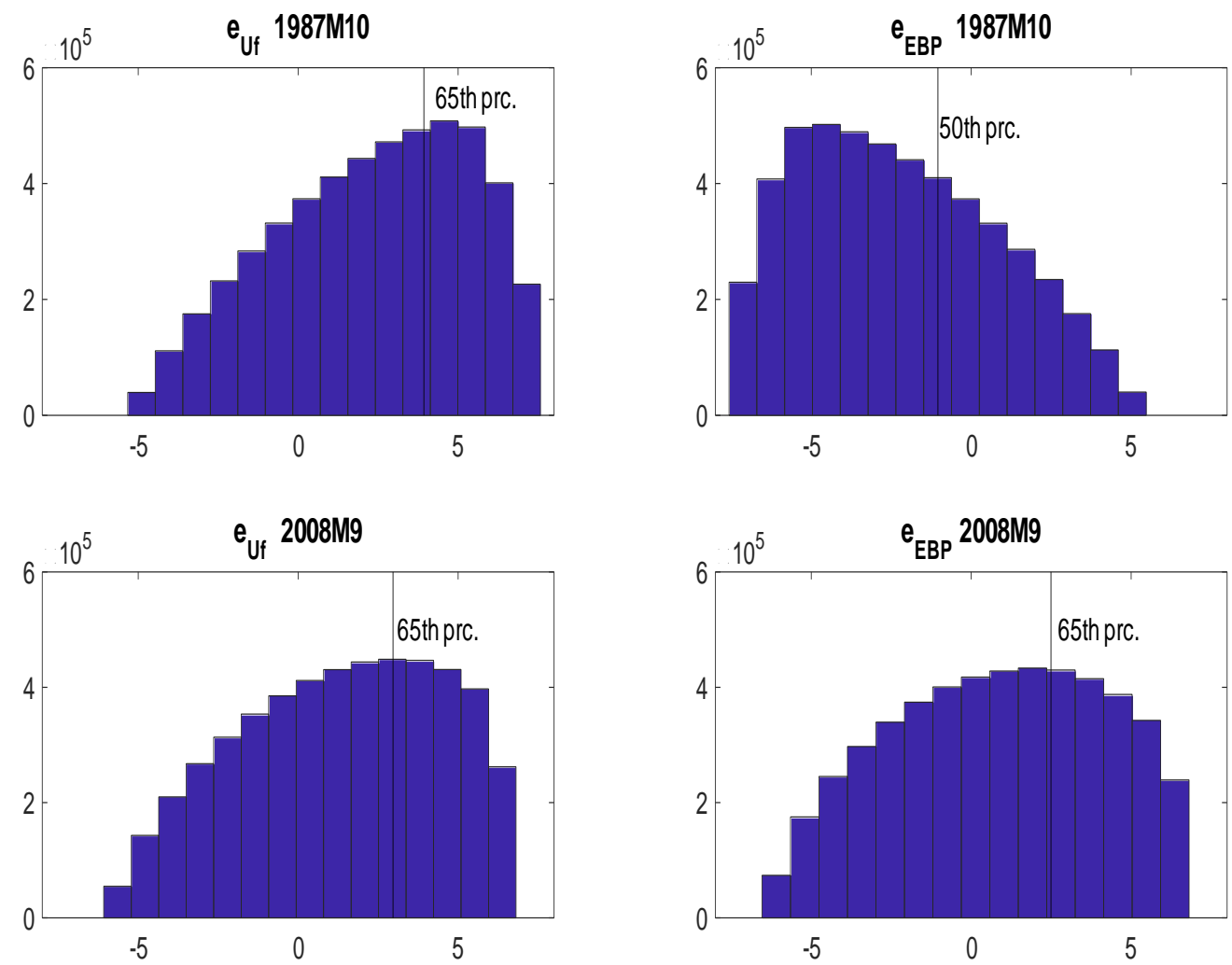

Figure 2: First and second moment shocks: Pre-identification empirical densities. Histogram based on 5 millions models. 

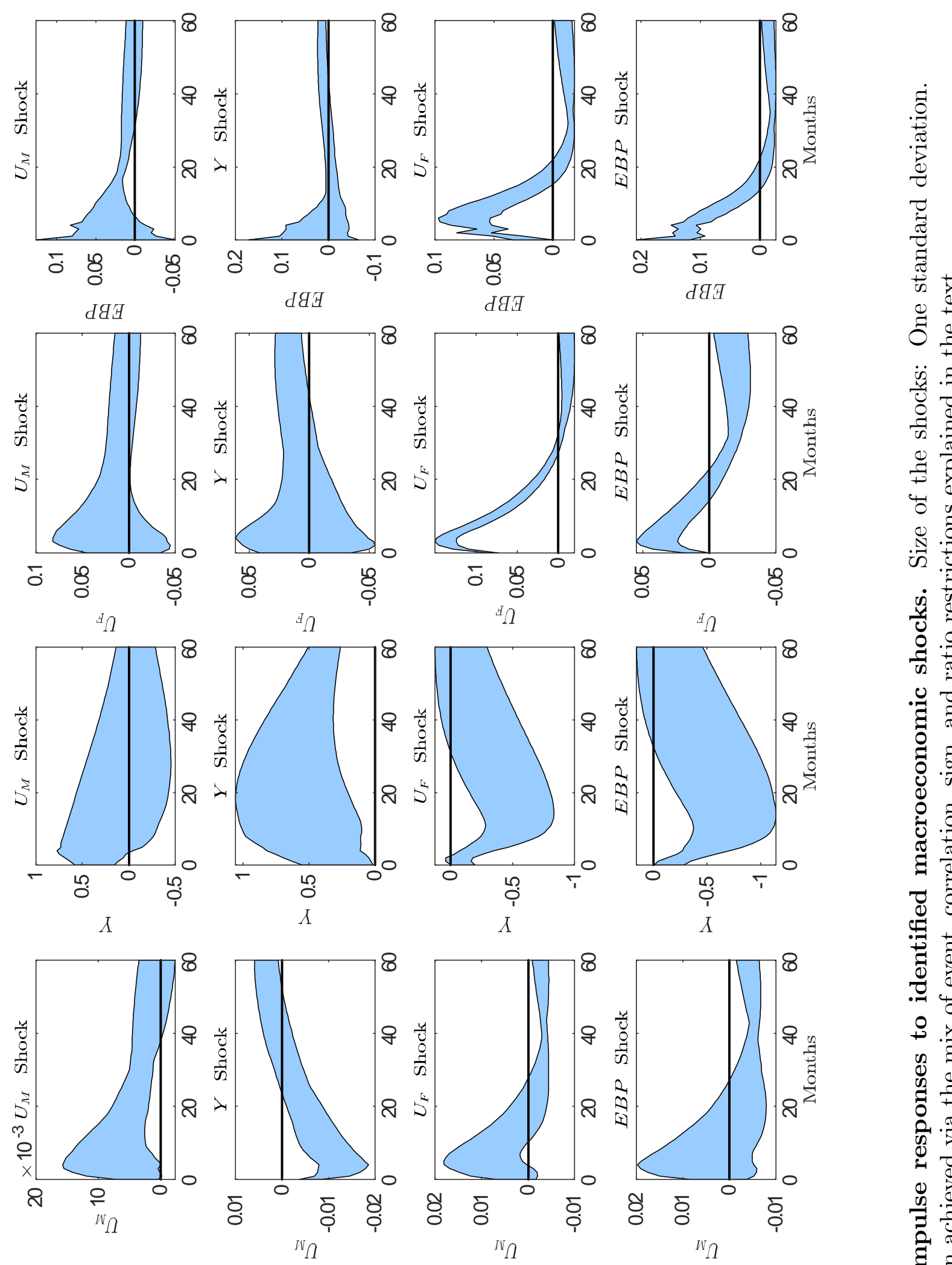

Ð

$\ddot{3}$.

ज.

舫

낭

옹

น

它

$\frac{2}{n} \stackrel{0}{\pi}$

. 금

ํㅣㄹ

ㅇํㅇ

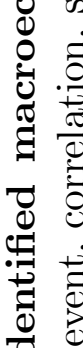

-

\&

Dै

究

D

造

쿄

ले

․․ㅁ

$\underset{0}{0}$ 


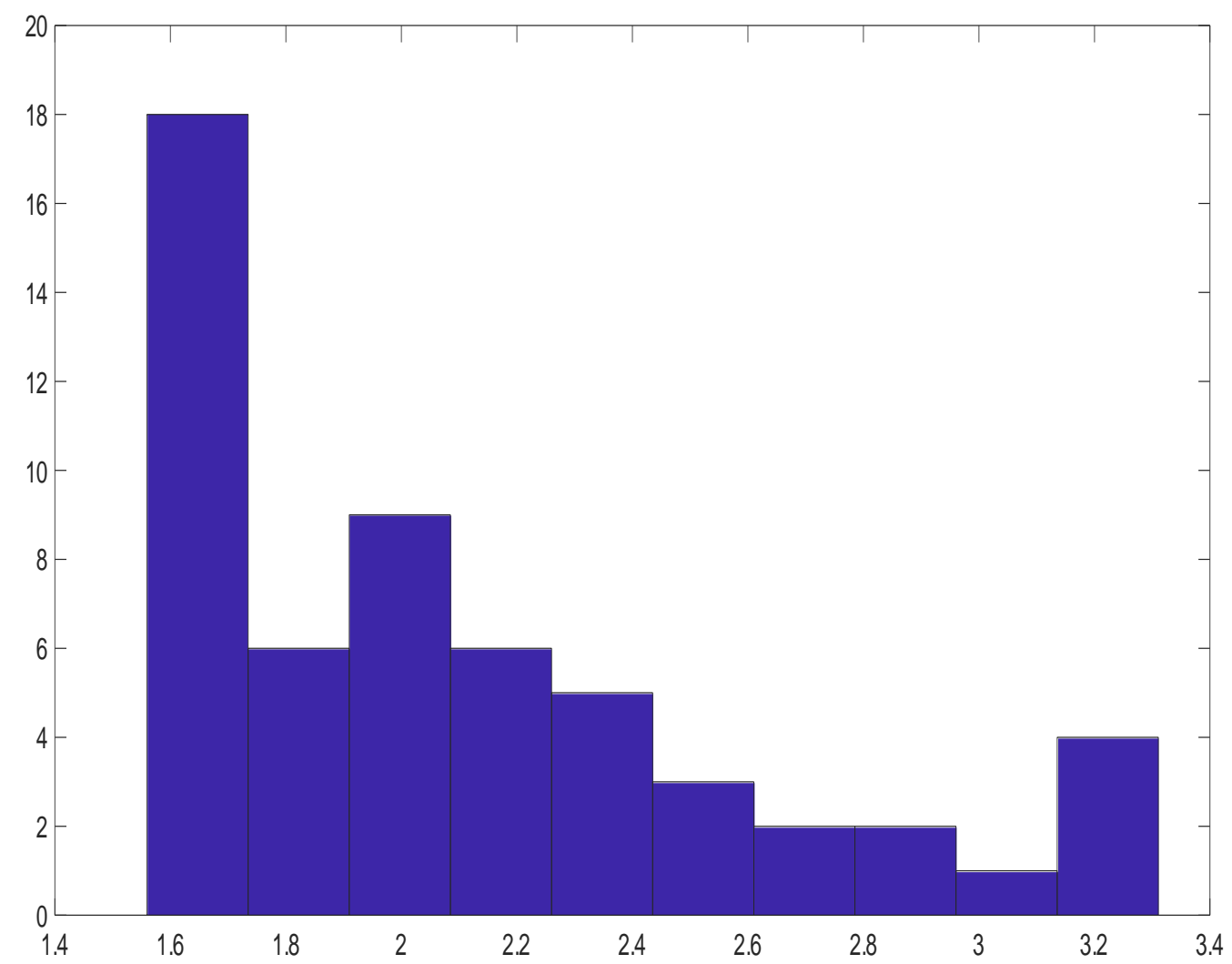

Figure 4: Finance Uncertainty Multiplier. Empirical distribution of the FUM across our 56 retained models. FUM computed by dividing (per each retained model) the peak response of output with endogenous EBP by the peak response of output with EBP set to zero at all horizons. 


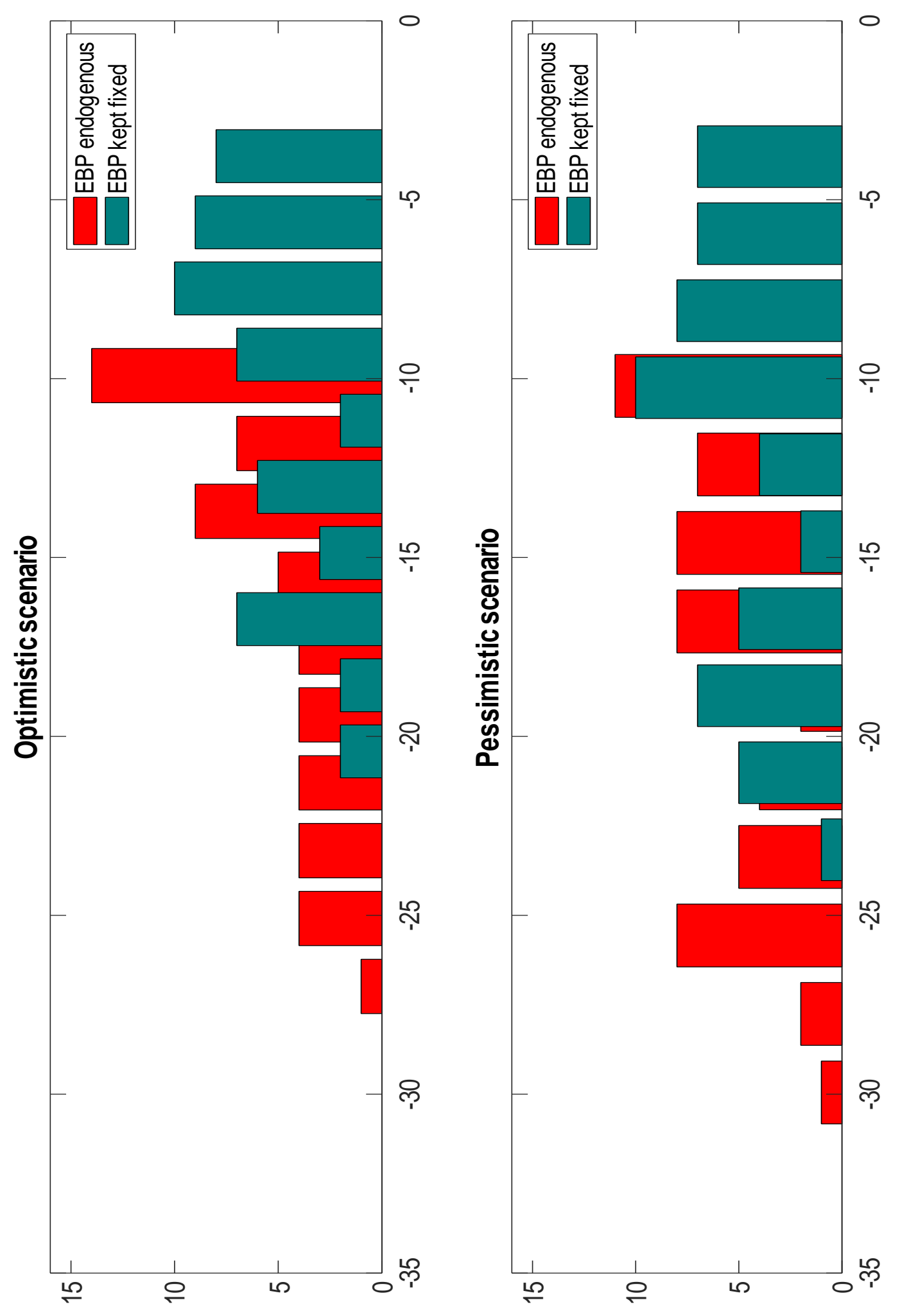

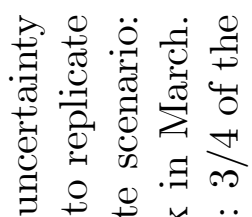

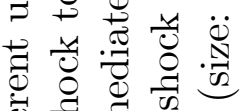

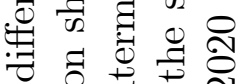

击. 离

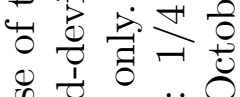

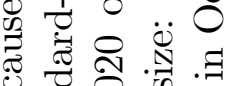

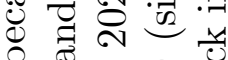

$\rightarrow$ 露 융

ฮี

氙诖芯氙

$\ddot{0} . \exists$ 。

\& จิ

궁 $\frac{9}{\pi} . \Xi$

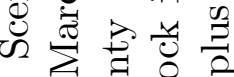
$\dot{0} . \exists$ 元

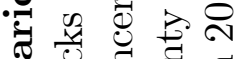
잉 饮苛芯 ‥ .

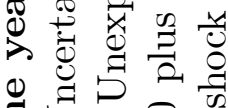
。ొ

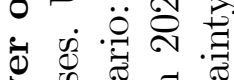

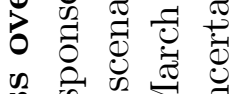

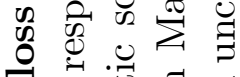

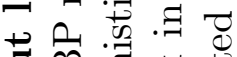
司可寻艺

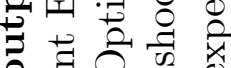
0

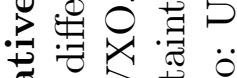
క $\exists$ 声

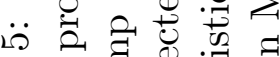
o 可 苟 


\section{Appendix of the paper "Financial Uncertainty and Real Activity: The Good, the Bad, and the Ugly" by Giovanni Caggiano, Efrem Castelnuovo, Silvia Del- rio, and Richard Kima}

This Appendix reports additional results with respect to those documented in the paper:

- Figure A1 puts in evidence the comovement between Ludvigson et al.'s (2019) financial uncertainty indicator (estimated by focusing on a prediction horizon $\mathrm{h}$ $=1$ month) and the VXO. The correlation between these two series is 0.83 .

- Figure A2 plots the correlations between our estimated macroeconomic shocks and those estimated by Ludvigson et al. (2019). The left panels of this Figure focus on the "Gmax" model, which is the single solution in the identified set for which the inequalities pertaining to the external variable constraints are collectively maximized, as measured by an equally-weighted quadratic norm. The right panels of Figure A2 plot the histograms of the correlations between our shocks (one per each one of models of our identified set) and the "Gmax" shock produced by Ludvigson et al. (2019).

- Figure A3 plots the histogram of the finance uncertainty multiplier (FUM) computed across our 56 retained models. FUM computed by dividing (per each retained model) the cumulative responses (over one year) of output with endogenous EBP by the cumulative responses of output with EBP set to zero at all horizons.

- Figure A4 plots the histograms of the finance uncertainty multiplier (FUM) computed across our retained models and conditional on simulations initialized with eight different seeds. FUM computed by dividing (per each retained model and seed) the peak (minimum) response of output with endogenous EBP by the peak response of output with EBP set to zero at all horizons. 


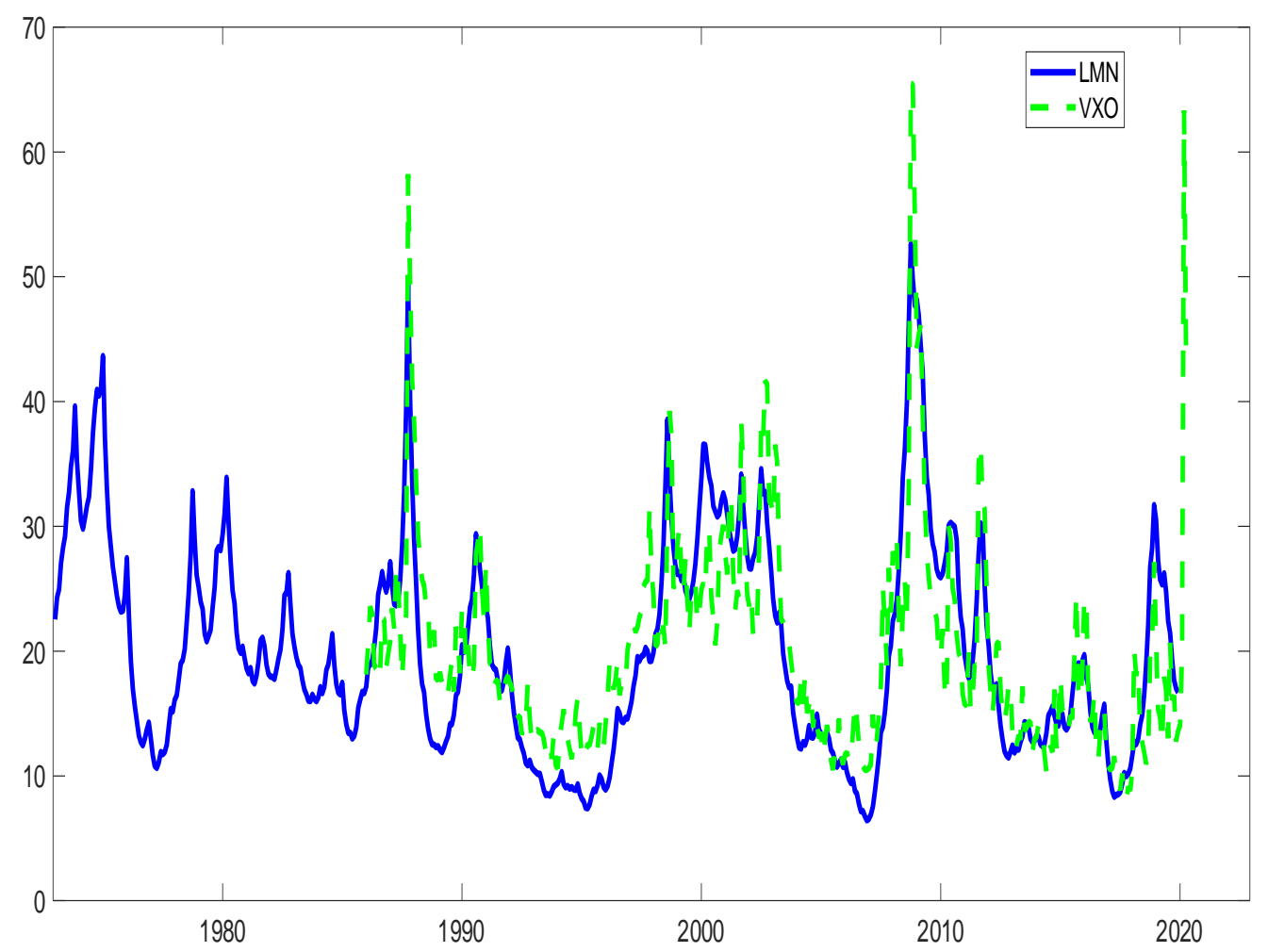

Figure A1: Financial Uncertainty as in Ludvigson, Ma, Ng (2019) vs. VXO. Correlation in the 1986M1-2019M12 sample: 0.83 . 

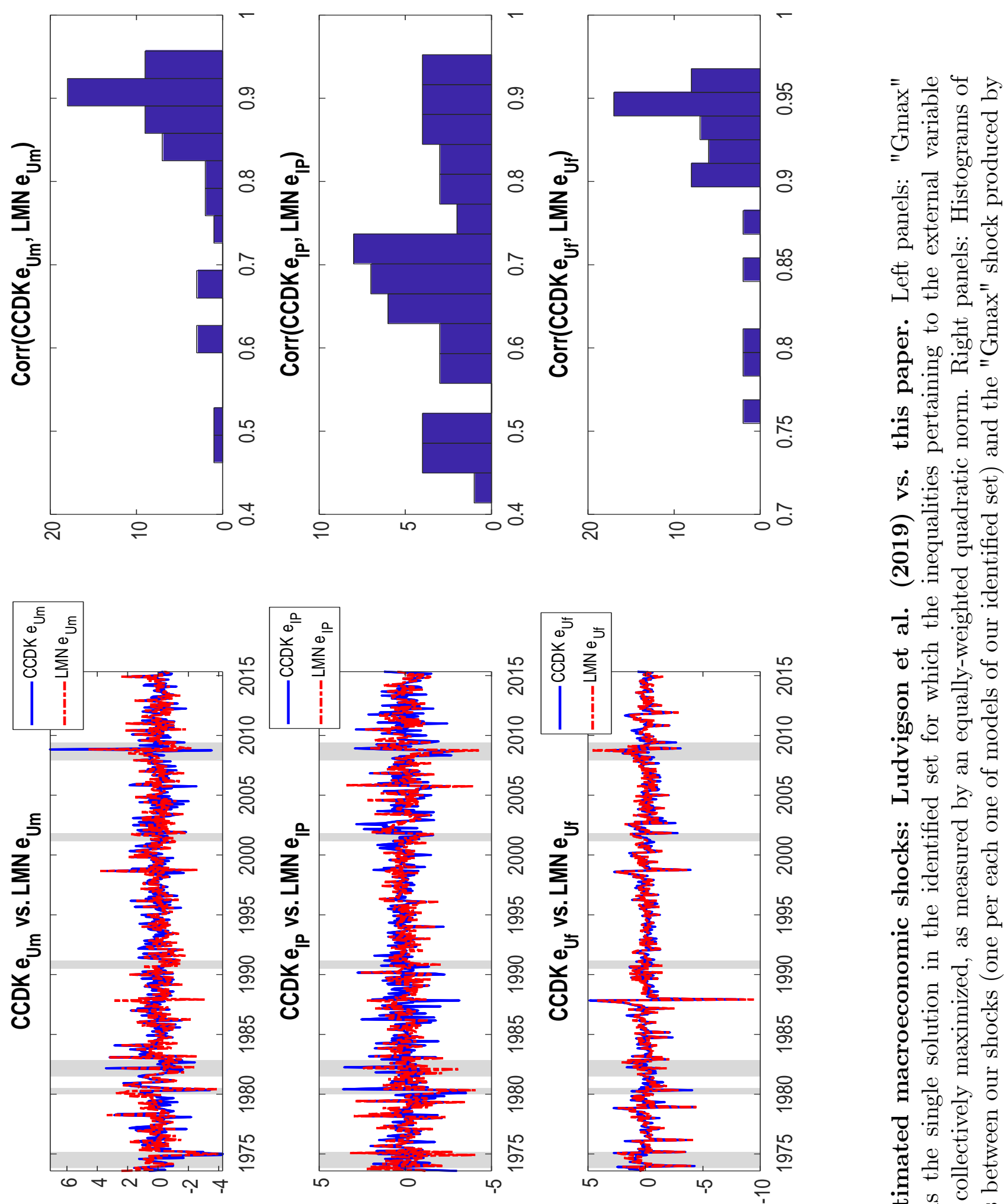
. 궁

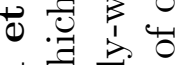
휴 丞舟 की 矛芯范 ज完过 $\ddot{0}$.

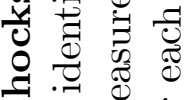
क .

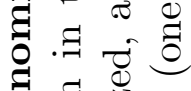

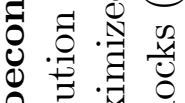
ญ

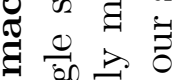

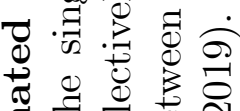
苞 苟 任 귱

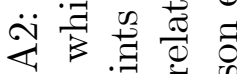

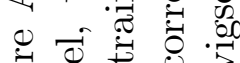

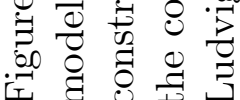




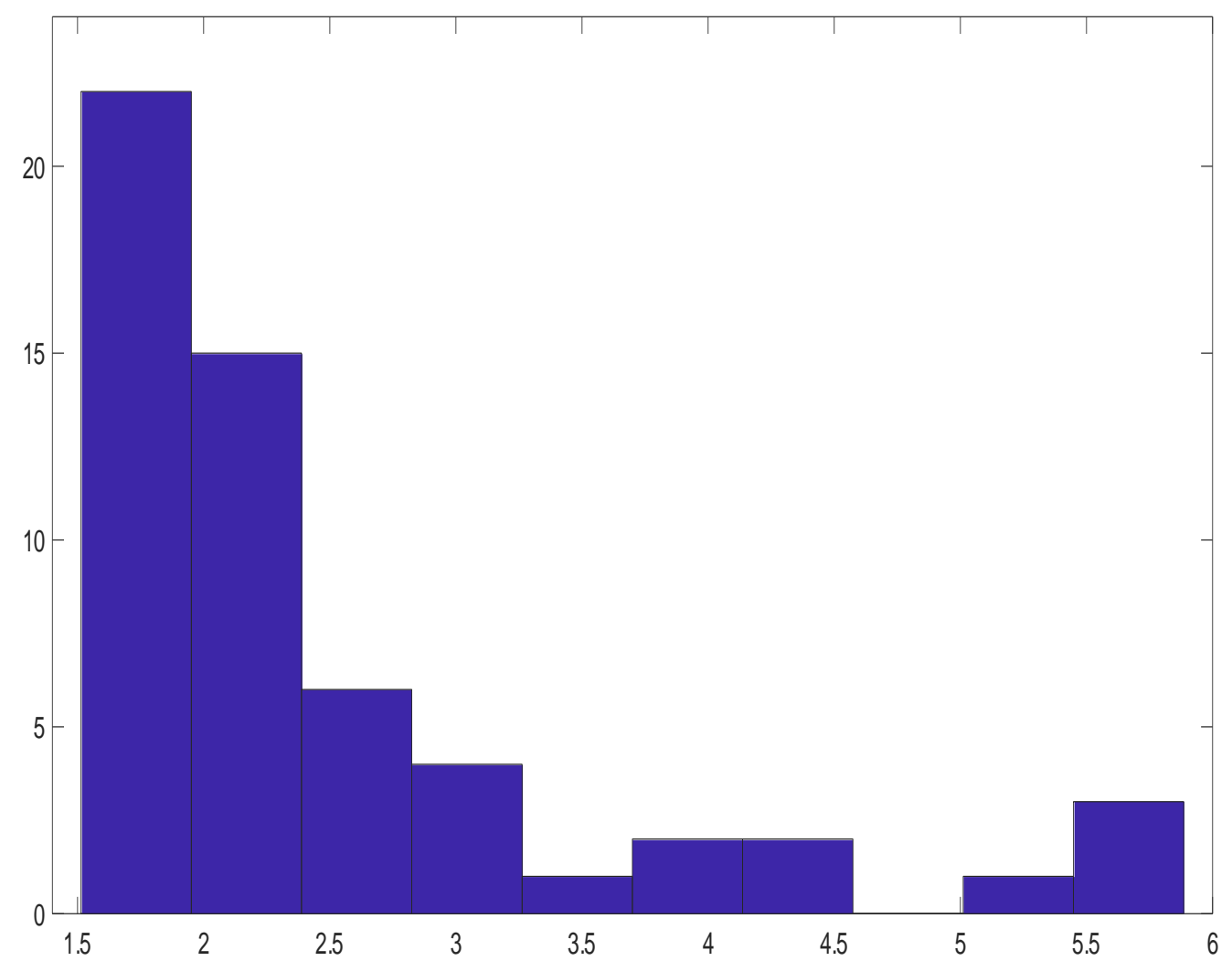

Figure A3: Finance Uncertainty Multiplier: Check with Cumulative Output Responses. Histogram of the FUM across our 56 retained models. FUM computed by dividing (per each retained model) the cumulative responses (over one year) of output with endogenous EBP by cumulative responses of output with EBP set to zero at all horizons. 

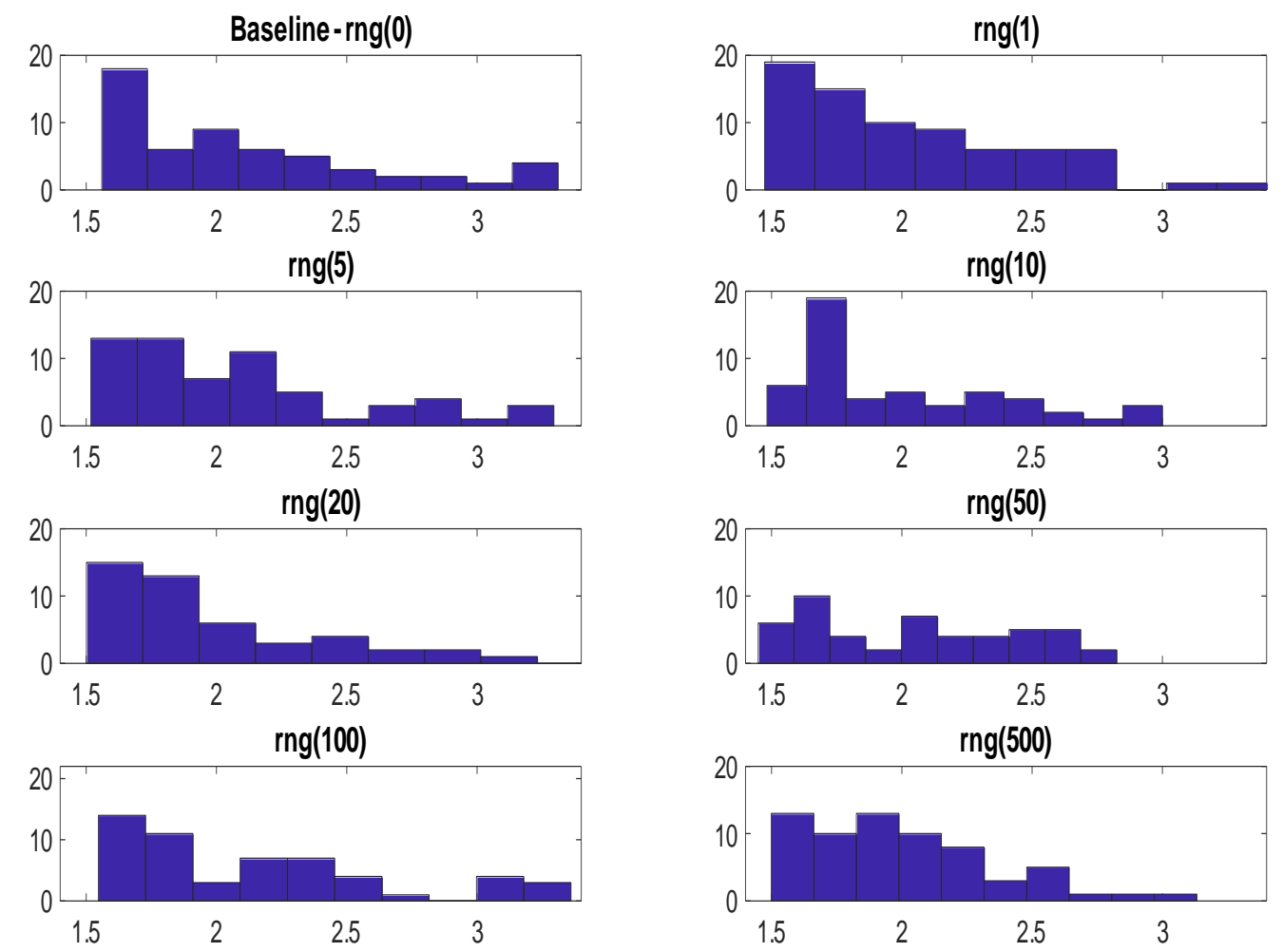

Figure A4: Finance Uncertainty Multiplier: Sensitivity to different seeds. Empirical distribution of the FUM across retained models conditional on different initial seeds for our stochastic simulations. Top-left panel: Baseline case (documented in the paper). FUM computed by dividing (per each retained model) the peak response of output with endogenous EBP by the peak response of output with EBP set to zero at all horizons. 